\title{
Editorial
}

\section{We Thank Our Peer Reviewers}

\author{
Seth S. Leopold MD
}

Received: 17 September 2013/Accepted: 30 September 2013/Published online: 9 October 2013

(C) The Association of Bone and Joint Surgeons ( 2013

Some things function so well that we only notice them when they don't work. Things like refrigerators, cars, fingers, knees, and shoulders come right to mind.

As does peer review.

While each of us bears the scars of a tough review received somewhere along the way-for many of us, more than one-the fact is that we owe a debt of gratitude to reviewers who, much more often than not, get it right. Their efforts improve our work, but they are not named or credited for this essential function.

Our journal could not exist without peer reviewers. Clinical Orthopaedics and Related Research ${ }^{\circledR}$ has processed in excess of 1500 papers this year; most of these will have been seen by at least three reviewers. Although our Deputy Editors and Associate Editors bring a great breadth and depth of experience to our journal, our roster of peer reviewers-which includes clinicians, scientists, policy experts, educators, and others-expands and

The author certifies that he, or any members of his immediate family, has no commercial associations (eg, consultancies, stock ownership, equity interest, patent/licensing arrangements, etc) that might pose a conflict of interest in connection with the submitted article.

All ICMJE Conflict of Interest Forms for authors and Clinical Orthopaedics and Related Research ${ }^{\circledR}$ editors and board members are on file with the publication and can be viewed on request. The opinions expressed are those of the writers, and do not reflect the opinion or policy of $C O R R^{\circledR}$ or the Association of Bone and Joint Surgeons ${ }^{\circledR}$.

S. S. Leopold ( $\square)$

Clinical Orthopaedics and Related Research, 1600 Spruce Street, Philadelphia, PA 19103, USA

e-mail: sleopold@clinorthop.org enhances our expertise, allowing us to work with papers on topics that range from physical anthropology to molecular genetics, and article types including clinical series, randomized trials, and massive epidemiological efforts. Each of those reviews likely took several hours of attention and care, a service for which the reviewers receive no compensation (and for which we do not charge authors).

In a specialty as diverse as ours, we simply could not have confidence in the validity and quality of the work we publish without the generosity and skill of our reviewers. For this, I would like to extend my personal gratitude to each referee who reviewed for $C O R R^{\circledR}$ in the last year; their names are listed here: DOI 10.1007/s11999-0133312-0.

I would like also to call attention to a much shorter panel: Our "Top Reviewer" list found at the top of the above list. Peer reviewers listed here live at the intersection of two important circles on our Venn diagram: The truly committed, and the extremely skillful. To make this list, a reviewer needed to complete four or more reviews between September 2012 and August 2013, and achieve an average review score in the "excellent" range. This is a special group, which represents less than $3 \%$ of the reviewers in our pool. I congratulate each of them on this great achievement, and I thank them for their special service to orthopaedic research and to our journal.

Finally, it is important to note that we do not list Editors who are on our masthead in the "Top Reviewer" list as they have already been recognized for their particular skill and expertise by being invited to serve on our Editorial Board. However, I would be remiss not to thank them here for their ongoing (and considerable) commitments to maintaining and improving quality in CORR ${ }^{\mathbb{R}}$. 